\title{
Transition Metal Complexes of Bidentate and Tridentate Ligands: From Optoelectronic Studies to Supramolecular Assemblies
}

\author{
Amlan K. Pal*
}

\begin{abstract}
This article depicts an overview of some of the research in supramolecular chemistry performed by the author over the past few years. This work includes the synthesis of building blocks, bidentate and tridentate 'super donor' ligands that are comprised of $\mathrm{H}$-hpp (where $\mathrm{H}$-hpp $=1,3,4,6,7,8$-hexahydro-2H-pyrimido[1,2-a] pyrimidine) coupled with various $N$-heterocycles as well as the synthesis and characterization of the transition metal complexes in self-assembled superstructures. The article also includes the studies of photophysical, electrochemical and density functional theory calculation of the complexes. Thus, the work relies on a combination of synthetic work and optoelectronic studies, and the results are relevant in the greater context of supramolecular chemistry, solar energy harvesting, and its conversion to chemical energy, photovoltaics and inorganic lightemitting device applications.
\end{abstract}

Keywords: Density functional theory (DFT) · Electrochemistry · NIR emitter · Photochemistry · Supramolecular chemistry

\section{Introduction}

As climate change becomes an ever-increasing concern, considerable research has been targeting artificial photosynthetic systems to duplicate natural photosynthetic complexes. By mimicking the chromophores used in light-harvesting complexes, e.g. carotenoids and chlorophylls, synthetic molecules may be combined in a fashion to harvest the excited-state energy. Thus, detailed studies of energy and electron transfer reactions may help lead to artificial photosynthetic devices. In this regard, our research in this area has focused on the design and synthesis of artificial chromophores and their incorporation into multinuclear arrays. One powerful new ligand that we developed is based on substituted guanidines in which the carbon of the central $\mathrm{CN}_{3}$ unit is incorporated into a bicyclic framework. They display favourable electronic and chemical characteristics as compared to their acyclic analogues. ${ }^{[1]}$ Undoubtedly, the most widespread applications of these ligands centre around the

\footnotetext{
${ }^{\star}$ Correspondence: Dr. A. K. Pal

Département de Chimie

Université de Montréal

2900 Edouard-Montpetit, Montréal

Québec H3T-1J4, Canada
}

E-mail: amlan.kumar.pal@umontreal.ca negatively charged amidinate, $\left[\mathrm{RC}\left(\mathrm{NR}^{\prime}\right)_{2}\right]^{-}$ and guanidinate $\left[\mathrm{R}_{2} \mathrm{NC}\left(\mathrm{NR}^{\prime}\right)_{2}\right]^{-}$anions ${ }^{[2]}$ and a considerable amount of work exists on the application of cationic amidinium and guanidinium salts, ${ }^{[3]}$ especially with respect to their anion-binding properties. Bicyclic guanidines containing two six-membered fused rings, such as H-hpp (where H-hpp = 1,3,4,6,7,8-hexahydro-2H-pyrimido[1,2-a]pyrimidine), have also been studied as bridging units of metal-dimers of general formula $\mathrm{M}_{2}(\mathrm{hpp})_{4}$ (where $\mathrm{M}=\mathrm{W}(\mathrm{II}), \mathrm{Mo}(\mathrm{II})$ ), ${ }^{[4]}$ and have been shown to act as powerful reducing agents, with record low ionization energies (onsets at 3.4 to $3.5 \mathrm{eV}$ ) and very negative oxidation potentials in THF $(-1.84$ to $-1.90 \mathrm{~V}$ vs. $\mathrm{Ag} / \mathrm{AgCl}) .^{[5]}$ On a similar note, a paddlewheel compound, [Os $\left.(\mathrm{hpp})_{4} \mathrm{Cl}_{2}\right]\left[\mathrm{PF}_{6}\right]$, has been synthesized that contains a rare $\mathrm{M}_{2}{ }^{7+}$ species and it was shown by means of EPR spectroscopy that the unpaired electron occupies a $\delta^{*}$-metal-based molecular orbital.[6] In the vast literature of structural diversity shown by the guanidinate backbone, hpp has also been used as chelating units in its $\eta_{1}^{-}, \eta_{2}^{-},\left(\eta_{1} \& \eta_{2}\right)$-mono and/ or bidentate forms with multivalent alkali/alkaline-earth and transition metals.[7] The linked bis(guanidine) ligand, such as $\mathrm{H}_{2} \mathrm{C}\{\mathrm{hpp}\}_{2}$, has been shown to be an excellent proton acceptor by virtue of hydrogen-bonding ${ }^{[8]}$ and has been applied to synthesize a coordinatively saturated aluminium cation, whereas, when deprotonated at the bridging methylene group to generate the corresponding carbanion, $\left[\mathrm{CH}\{\mathrm{hpp}\}_{2}\right]^{-}$, the latter acts as a rare aliphatic $N, C, N$ '-pincer ligand to coordinate with silicon and tin. ${ }^{[9]}$ The 'superbasicity' of $\mathrm{CH}_{2}\{\mathrm{hpp}\}_{2}(\mathrm{pK}$ of its conjugate acid in $\mathrm{MeCN} \sim 29$ ) has also been proven by Coles et al. by means of a combination of sophisticated analytical techniques, e.g. solid-state CPMAS ${ }^{15} \mathrm{~N}$ NMR spectroscopy, variable temperature high-resolution $\mathrm{X}$-ray data and computational analysis and spectrometric titrations in MeCN. ${ }^{[10]}$ Apart from these structural and electronic modulations of the complexes containing the hpp unit, guanidinate ligands also find applications in (i) $\mathrm{C}=\mathrm{N}$ bond metathesis, ${ }^{[11]}$ (ii) as a base in $\mathrm{C}-\mathrm{N}$ cross coupling reactions, ${ }^{[12]}$ (iii) as an organocatalyst in aminolysis of esters, ${ }^{[13]}$ (iv) also in various organic transformations, such as Michael reactions, Wittig reactions, ring-opening polymerizations, Knoevenagel condensations, deprotection reactions ${ }^{[14]}$ and Tishchenko reaction for synthesis of esters. ${ }^{[15]}$

Although the use of bidentate ligands containing the hpp unit has been poorly explored in the literature, tridentate ligands comprising of hpp units and the heavy transition metals of both bidentate and tridentate ligands have never been explored. Our group recently started exploiting strongly donating multidentate ligands containing hpp units and studied their metal complexes in light of electrochemical, photophysical and DFT calculations and recent results along this line are presented in this article. 


\section{Bidentate Chelating Ligands Containing hpp}

In a recent article we demonstrated the synthesis of a library of bidentate and tridentate chelating ligands capable of forming six-membered chelate rings with transition metal ions, such as Ru(II) or Re(I), compared to the formation of five-membered chelate rings by bpy (bpy $=2,2^{\prime}$-bipyridine) or tpy (tpy $=2,2^{\prime}: 6^{\prime}, 2^{\prime \prime}$-terpyridine). ${ }^{[16]}$ The ligands were synthesized by conventional $\mathrm{C}-\mathrm{N}$ bond forming reaction using different $\mathrm{N}$-haloheterocycles and H-hpp in presence of $\mathrm{Pd}(\mathrm{OAc})$ and rac-BINAP (BINAP = (2,2'-bis(diphenylphosphino)-1,1'-binaphthyl)) (Fig. 1). The incorporation of the hpp moiety was shown to be equally effective with $N$-haloheterocycles containing both electron withdrawing (such as $-\mathrm{NO}_{2}$, $-\mathrm{COCH}_{3}$ ) and electron donating (such as -Me, $-\mathrm{OMe}$ ) substituents as well as with varying numbers of ring nitrogen atoms at different positions, e.g. pyridine, pyrimidine and pyrazine. The reaction was shown to be sluggish in presence of carboxylic acid group (ligand L13, Fig. 1) as the basic H-hpp moiety ( $\mathrm{pK}_{\mathrm{a}}$ of its conjugate acid 26 in acetonitrile) is easily protonated during the progress of the reaction.

Ligands L1-L5 were employed as ancillary ligands in the syntheses of complexes with $c i s-\left[\mathrm{Ru}(\mathrm{bpy}){ }_{2} \mathrm{Cl}_{2}\right]$ (Scheme 1).[17] The resulting complexes, 1-5, exhibited approximately $500 \mathrm{mV}$ less positive oxidation potentials of the metals, which are quasi-reversible in nature, compared to that of $\left[\mathrm{Ru}(\mathrm{bpy})_{3}\right]^{2+}(1.27 \mathrm{~V}$ vs. SCE), whereas the first quasi-reversible ligand-based reductions for complexes 1, 2, 4 and 5 were 20-600 mV cathodically shifted compared to that of $\left[\mathrm{Ru}(\mathrm{bpy})_{3}\right]^{2+}(-1.35 \mathrm{~V}$ vs. SCE $)$. These data clearly indicate very strong electron donation from the ancillary ligand as compared to bpy. The $100 \mathrm{mV}$ anodic shift of the first reduction potential of complex 3 , compared to that of $\left[\mathrm{Ru}(\mathrm{bpy})_{3}\right]^{2+}$, was attributed to the strong $\pi$-acceptance of pyrazine moiety as compared to that of pyridine or pyrimidine moiety. The electrochemical data were shown to be in good agreement with the Density Functional Theory (DFT) calculations. The higher energies calculated for the HOMO of $[\mathbf{1}]^{2+}(-5.51 \mathrm{eV})$, $[2]^{2+}(-5.64 \mathrm{eV})$, and $[5]^{2+}(-5.72 \mathrm{eV})$ in comparison to that of $\left[\mathrm{Ru}(\mathrm{bpy})_{3}\right]^{2+}(-6.11$ $\mathrm{eV}$ ) were in good agreement with the lower anodic potentials measured for $\mathbf{1}, \mathbf{2}$, and $\mathbf{5}$ in comparison with $\left[\mathrm{Ru}(\mathrm{bpy})_{3}\right]^{2+}$. In UVvis spectroscopy, the lowest energy singlet metal-to-ligand charge-transfer $\left({ }^{1} \mathrm{MLCT}\right)$ absorption peaks of complexes $\mathbf{1}-\mathbf{5}$ were found at $530-560 \mathrm{~nm}$, which is considerably red-shifted by $\sim 100 \mathrm{~nm}$ compared to that of $\left[\mathrm{Ru}(\mathrm{bpy})_{3}\right]^{2+}$, again indicating strong donation from the ancillary ligand, so that the metal highest occupied molec-

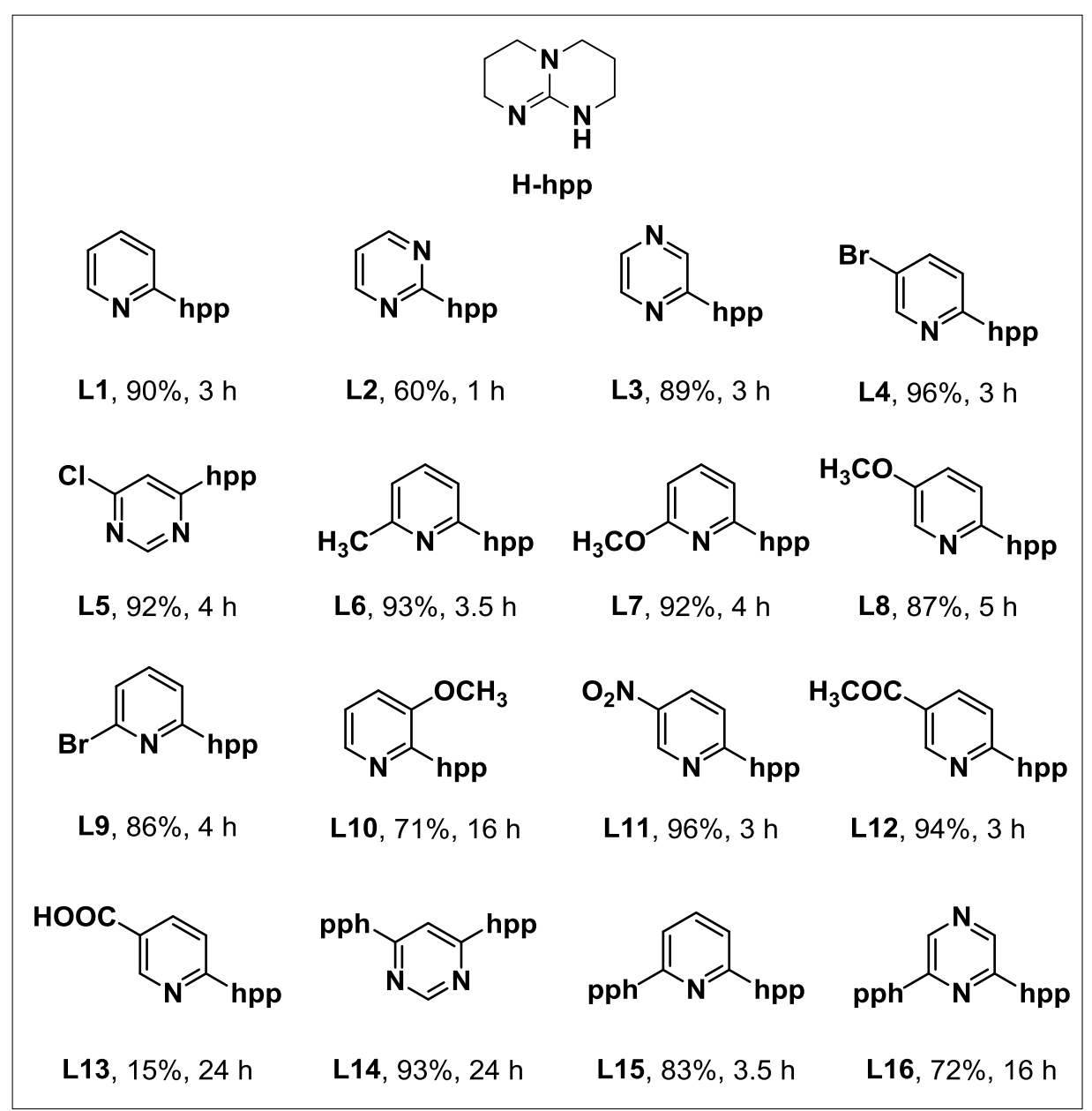

Fig. 1. Different bidentate and tridentate chelating ligands with their yield and time of syntheses. ${ }^{[16]}$

ular orbital (HOMO) is higher in energy, whereas the bpy-based lowest unoccupied molecular orbitals (LUMO) remains unaffected, resulting in a red-shift of the absorption band. Concomitant to the red-shift in the ${ }^{1}$ MLCT absorption band, the lowest energy emission bands of complexes 1-5 were also red-shifted by $\sim 120 \mathrm{~nm}$ compared to that of $\left[\mathrm{Ru}(\mathrm{bpy})_{3}\right]^{2+}$. The spectroscopic data were also shown to be in line with the time-dependent-DFT (TD-DFT) calculations. The room temperature excited-state lifetime $(\tau)$ and phosphorescence quantum yield $\left(\Phi_{\mathrm{PL}}\right)$ values of complexes 1-5 were found to be significantly lower compared to that of $\left[\mathrm{Ru}(\mathrm{bpy})_{3}\right]^{2+}$, presumably due to lower symmetric octahedral geometry in complexes 1-5 and vibrational deactivation through the aliphatic $\mathrm{C}-\mathrm{H}$ bonds in the saturated guanidine backbone.

In search of transition metal complexes that exhibit longer room temperature $\tau$ and higher $\Phi_{\mathrm{PL}}$, but not affecting the red-shifted absorption and emission profiles, we sought to develop a bis-bidentate ligand which can give rise to a dimetallic complex. In this context, ligand L14 was synthesized by microwave heating and in neat conditions using 1 equiv. of 4,6-dichloropyrimidine and 4.2 equiv. of $\mathrm{H}$-hpp, such that H-hpp acts as its own base. ${ }^{[18]}$ Ligand L14 thus synthesized displayed parallel-coordination vectors to complex with $c i s-[\mathrm{Ru}(\mathrm{b}-$ py) ${ }_{2} \mathrm{Cl}_{2}$ ] and furnished a di-Ru(II,II) complex, $\mathbf{6}$, that exhibited enhanced stereose-

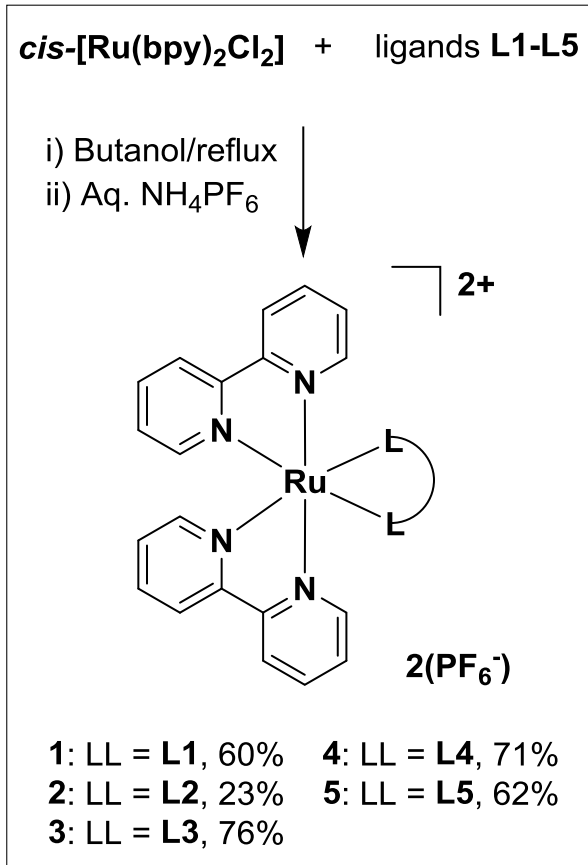

Scheme 1. Syntheses of complexes 1-5 containing ancillary ligands L1-L5. ${ }^{[17]}$ 
lectivity as its meso-form over its homochiral racemic-form [diastereoselectivity of $1: 13: 1(\Lambda \Lambda: \Lambda \Delta($ or $\Delta \Lambda): \Delta \Delta)$ ] (Scheme 2). Similar selectivity of a $\Lambda \Lambda \Delta$ form in a tri-Ru(II,II,II) complex has also been shown $[\Lambda \Lambda \Lambda: \Lambda \Lambda \Delta(=\Delta \Lambda \Lambda): \Lambda \Delta \Lambda=4: 9: 1]$ by Hanan and coworkers. ${ }^{[19]}$ Due to strong onset face-to-face $\pi-\pi$ interactions involving two bpys, complex 6 was isolated as its meso form without any chiral-column purification. Several other mono-ruthenium(II) complexes, 7-9, were isolated in modest yields during the synthesis of complex 6 based on the solvolysis of the $\mathrm{C}-\mathrm{N}$ bond of ligand $\mathbf{L 1 4}$ as its mono-ruthenium(II) adducts, which may suggest that the ligated-hpp moiety can act as a leaving group when protonated. ${ }^{[20]}$ In cyclic voltammetry complex 6 exhibited two quasi-reversible $\mathrm{Ru}$-based oxidations, as the HOMO and HOMO-1 were predominantly centred on the metal centres in its +4 and +5 oxidation states respectively, as suggested by DFT calculations. The first and second oxidation potentials were $\sim 400$ and 260 $\mathrm{mV}$ less positive respectively, to that of $\left[\mathrm{Ru}(\mathrm{bpy})_{3}\right]^{2+}$, again indicating strong electron donation from the saturated aliphatic guanidine backbone. The comproportionation constant $\left(\mathrm{K}_{\mathrm{c}}\right)$, which is the measure of intermetallic-interaction in complex $\mathbf{6}$, was found to be 506 and this value is very similar to a diruthenium(II,II) complex containing 4,6-di(2-pyridyl)pyrimidine as the bridging ligand as observed by Keene $e t$ al. and in other pyrimidine-based ligands. ${ }^{[21]}$ The low value of $\mathrm{K}$ indicated that the metal-ions were weakly interacting through direct orbital overlap of metal-d orbitals due to short internuclear separation of 5.9 $\AA$. As predicted, complex $\mathbf{6}$ also exhibited red-shifted ${ }^{1}$ MLCT and ${ }^{3}$ MLCT maxima at $511 \mathrm{~nm}$ and $739 \mathrm{~nm}$, respectively. Data of more interest were the room temperature $\tau$ and $\Phi_{\mathrm{PL}}$ values of complex $\mathbf{6}$, which were almost two-fold enhanced compared to those of complexes 1-5.

The mono-ruthenium(II) analogues, which were found to form as solvolysis products of the Ru(bpy) $-\mathbf{L} \mathbf{1 4}$ adduct, also exhibited less positive oxidation potentials than $\left[\mathrm{Ru}(\mathrm{bpy})_{3}\right]^{2+}$. The butoxy adduct $(\mathbf{8})$ showed the lowest positive oxidation potential at $0.70 \mathrm{~V}$, followed by the ethoxy adduct (7) at $0.89 \mathrm{~V}$, whereas the least donating $-\mathrm{OCH}_{2} \mathrm{CH}_{2} \mathrm{OH}$ adduct (9) exhibited an oxidation potential at a value of $1.05 \mathrm{~V}$. These values were found to be in good agreement with the DFT-calculated energies of HOMOs $\left(\mathrm{E}_{\mathrm{HOMO}}=-5.58\right.$ $\mathrm{eV}, \mathrm{E}_{\mathrm{HOMO}(8)}=-5.56 \mathrm{eV}, \mathrm{E}_{\mathrm{HOMO}(9)}=-5.65$ $\mathrm{eV})$ and the Hammett $\left(\sigma_{\mathrm{H}}\right)$ parameters of different alkoxy-ether groups $\left(\sigma_{\mathrm{H}(\text { butoxy })}=\right.$ $-0.32, \sigma_{\mathrm{H}(\text { ethoxy })}=-0.24$ and $\sigma_{\mathrm{H}(\text { ethyleneglycoxy }}$ $=-0.12)$. Complexes 7-9 again displayed red-shifted ${ }^{1}$ MLCT maxima (538-552 $\mathrm{nm})$ and NIR emission (646-743 nm). The effect of $\sigma$-donation from the different alkoxy adducts were much more pronounced in the red-shift of emission maxima from complex $9\left({ }^{3}\right.$ MLCT at 646 $\mathrm{nm})$, to complex 7 ( ${ }^{3} \mathrm{MLCT}$ at $\left.695 \mathrm{~nm}\right)$ to complex $8\left({ }^{3} \mathrm{MLCT}\right.$ at $\left.743 \mathrm{~nm}\right)$. Although these complexes were electrochemically appealing due to easy and quasi-reversible metal-based oxidations, the photophysical properties, i.e. the room temperature excited-state lifetime $(\tau)$ values and photoluminescence quantum yields $\left(\Phi_{\mathrm{PL}}\right)$ were much lower than those of $\left[\mathrm{Ru}(\mathrm{bpy})_{3}\right]^{2+}$, again presumably due to a break in octahedral symmetry in complexes 7-9 and higher values of non-radiative decay constant $\left(k_{n v}\right)$ in the presence of aliphatic $\mathrm{C}-\mathrm{H}$ bonds. However, the phenomenon of solvolysis opens up a new possibility of developing higher nuclearity complexes based on a dendrimer approach using the alkoxy group.

Since the ruthenium complexes of bidentate ligands were found to be devoid of $\operatorname{good} \tau$ and $\Phi_{\mathrm{PL}}$ values, even though they exhibited red-shifted absorption and NIR emission, a property much desired for cell-culture in inorganic-biochemistry, ${ }^{[22]}$ we recently became interested in synthesizing and exploring the optoelectronic properties of $\operatorname{Ir}(\mathrm{III})$-complexes containing bis-ppy (where ppy = phenylpyridinato) and $\mathbf{L 1}$ and $\mathbf{L 3}$ as the ancillary ligands (Scheme 3).[23] The heteroleptic Ir(III) complexes, 10-12, were synthesized in good yields by cleaving the chloro-bridged Ir(III,III)-dimer in presence of the ancillary ligands $\mathbf{L 1}$ or $\mathbf{L 3}$ in a mild reaction condition. Similar to their ruthenium analogues, these complexes also exhibited easy oxidation (0.99-1.21 V vs. SCE) compared to their parent prototypes, such as [(ppy) $)_{2} \mathrm{Ir}$ (bpy) $]\left[\mathrm{PF}_{6}\right]\left(\mathrm{E}_{1 / 2}^{\text {ox }}=1.27 \mathrm{~V}\right.$ vs. SCE $)$ and $\left[(\mathrm{dFMeppy})_{2} \operatorname{Ir}(\mathrm{bpy})\right]\left[\mathrm{PF}_{6}\right]\left(\mathrm{E}_{1 / 2}{ }^{\text {ox }}=1.55 \mathrm{~V}\right.$ $v s$. SCE). These oxidations were assigned to a concomitant removal of an electron from both metal- and ligand-based orbitals as the HOMOs of 10-12 were constituted almost equally with iridium and the $\mathrm{C}^{\wedge} \mathrm{N}$ ligands, as suggested by DFT calculations. Concomitant to the electrochemical data the lowest energy absorption maximum was also red-shifted by $23-41 \mathrm{~nm}$ compared to that of $\left[(\mathrm{ppy})_{2} \operatorname{Ir}(\mathrm{bpy})\right]\left[\mathrm{PF}_{6}\right]\left(\lambda_{\max }=\right.$ $420 \mathrm{~nm})$. These complexes exhibited blueto-green emission (470-503 nm), a very desirable feature for recent device applications in inorganic-LED and light-emitting electrochemical cells (LEECs). Most importantly, unlike the ruthenium complexes 1-9, these complexes displayed improved room temperature $\tau$ (up to 2.6 $\mu \mathrm{s})$ and $\Phi_{\mathrm{PL}}(0.2-61.8 \%)$ values, due to the enlarged energy gap between the emissive triplet state and non-emissive triplet metal-centred ( $\left.{ }^{3} \mathrm{MC}\right)$ states, so that thermally activated internal conversion (TAIC) from emissive triplet state to ${ }^{3} \mathrm{MC}$ state is now decreased.

\section{Moving from Bidentate to Tridentate Chelating Ligands Containing hpp}

Transition metal complexes of bidentate bpy or phen (phen $=1,10$-phenanthroline) ligands are photophysically appealing

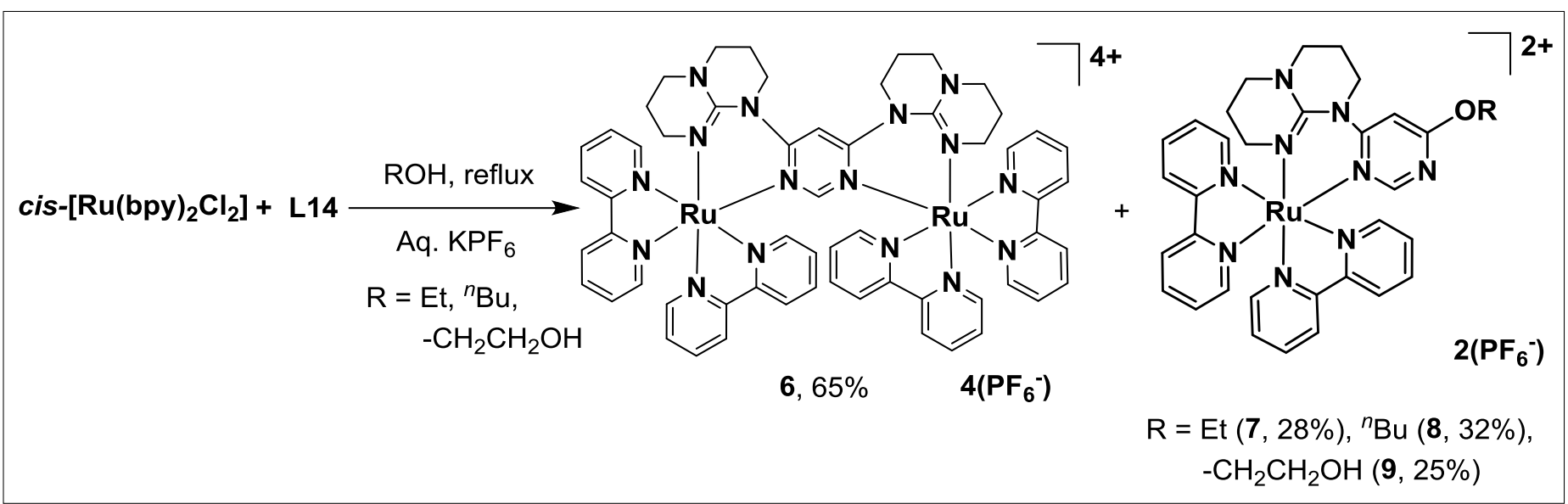

Scheme 2. Synthesis of a bis-Ru(I,II) complex (6) and some mono-Ru(II) complexes (7-9) as solvolysis products of complex 6 in different alcoholic solvents. ${ }^{[18,20]}$ 


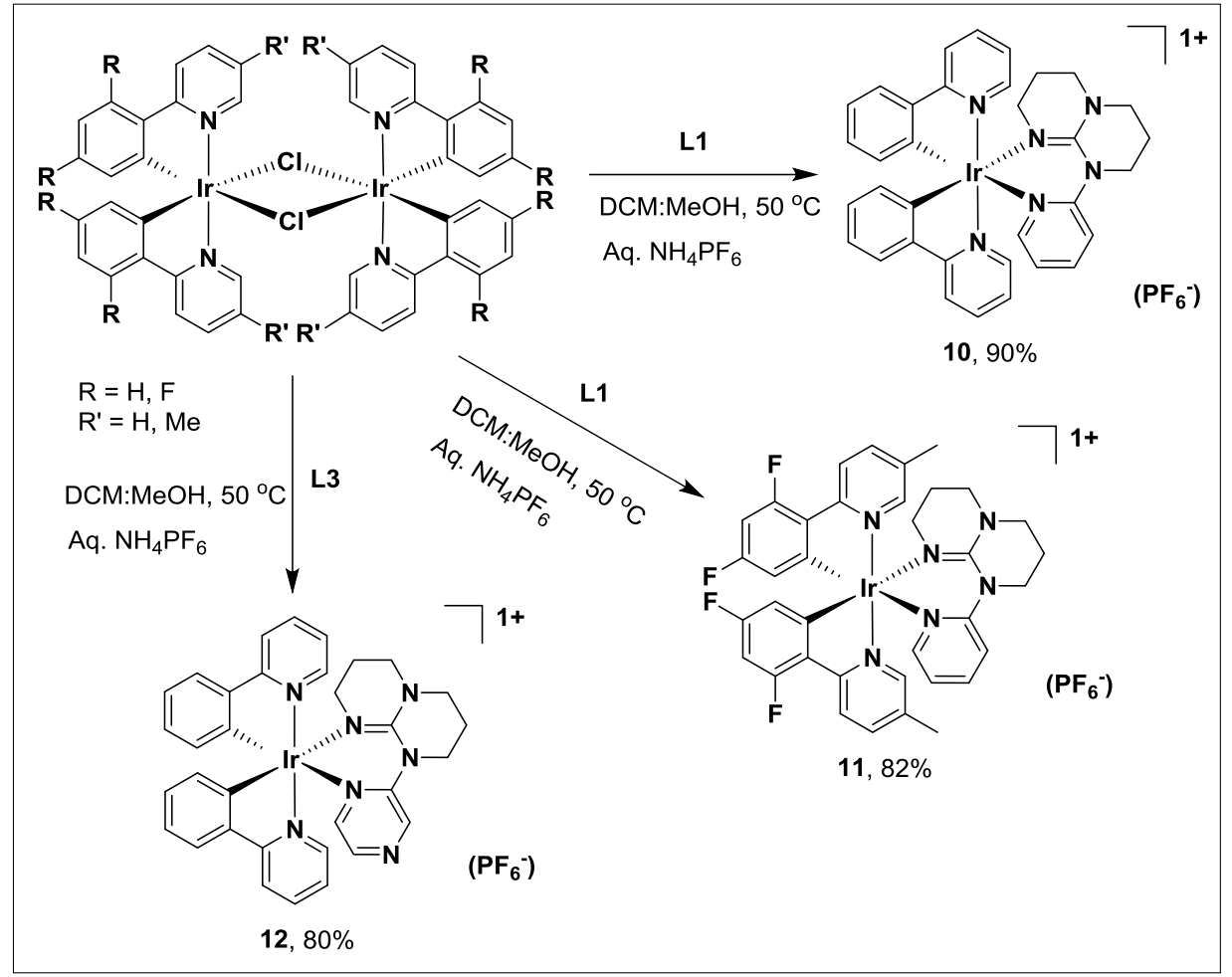

Scheme 3. Synthesis of heteroleptic Ir(III)-complexes containing L1 and L3 as the ancillary ligands. [23]

as they typically exhibit long $\tau$ and $\Phi_{\mathrm{PL}}$ values. Enantiopure synthesis of these types of complexes is rather cumbersome, as the crude synthesis generally gives rise to a racemic mixture of chiral- $\Lambda$ or $-\Delta$ enantiomers, thus rendering these types of complexes unsuitable for cell-culture as DNA probes and vectorial energy transfer in material chemistry, whereas transition metal complexes of tridentate ligands as tpy or $\mathrm{dpt}(\mathrm{dpt}=2,6$-dipyridyltriazine $)$ are attractive alternatives as (i) they are achiral due to inherent $\mathbf{C}_{2}$ symmetry, and thus devoid of stereospecific syntheses, (ii) can exhibit vectorial electron and energy transfer due to their linear geometry. The tridentate complexes, however, exhibit poor photophysical properties at room temperature $\left(\tau\right.$ and $\Phi_{\mathrm{PL}}$ values of $\left[\mathrm{Ru}(\mathrm{tpy})_{2}\right]^{2+}$ are 0.25 ns and $\leq 1 \times 10^{-5}$, respectively). ${ }^{[24]} \mathrm{We}$, thus, recently became interested in synthesizing different tridentate ligands and exploring their optoelectronic properties as well as studying their self-assembly processes.

We started with the synthesis of ligand L17 or 3-PyTpy (where 3-PyTpy = 4'-(3-pyridyl)-2,2':6'2"-terpyridine) and synthesizing their metal complexes with $\mathrm{Fe}$ (13), Ru (14), Co (15), Ni (16), Cu (17) complexes, where the metal ions are in their divalent states (Scheme 4). ${ }^{[25]}$ The one-pot synthesis of $\mathbf{L 1 7}$ included a cyclisation reaction involving a diketone and an ammonia molecule. [26] Complexes 13-17 were obtained using 2:1 stoichiometric ratio of ligand:metal in a chloroform/ethanol/acetone solution at reflux for 1-2 tion at the electrode surface and slow ex- change of electrons between the electrode and $\mathrm{Ni}$ (III) ions. In UV-vis spectroscopy, complexes 13 and 14 exhibited characteristically intense ${ }^{1}$ MLCT transitions, whereas complexes $\mathbf{1 5}$ and $\mathbf{1 7}$ displayed weak metal-centred d-d transitions in the red and NIR region with very low molar absorptivity (10-40 $\left.\mathrm{M}^{-1} \mathrm{~cm}^{-1}\right)$. Among complexes 13-17, only complex 14 exhibited an emission at $\sim 695 \mathrm{~nm}$ at room temperature, as the TAIC process occurs at a very fast rate at room temperature for the other complexes.

Complexes 13 and 14 were further studied for self-assembly studies with neutral trans-directing $\mathrm{PdCl}_{2}$ binding units using the $60^{\circ}$ coordination vector of the heteroatoms in the pendant 3-pyridyl units, as mentioned above (Scheme 5).[27] A diverse and sufficient number of supramolecular assemblies are already known in literature, ${ }^{[28]}$ but the uniqueness of this self-assembly lies in the use of neutral $\mathrm{PdCl}_{2}$ units instead of cis-protected $\mathrm{Pd}(\mathrm{II})$, $\mathrm{Pt}(\mathrm{II})$ or $\operatorname{Re}(\mathrm{I})$-corners. [29] The self-assembly process gave rise to hexametallic discrete structures that were shown to proceed in polar, non-coordinating solvent such as nitromethane, whereas acetonitrile and dimethylsulfoxide were found to be competitive against the metalloligands, i.e. complexes 13 and 14. Similar syntheses of triangular discrete assemblies with neutral $\mathrm{PdCl}_{2}$ binding units also used highly polar non-coordinating solvent mixtures. ${ }^{[30]}$ The resulting assemblies were studied by solution NMR, HR-MS, elemental analysis (EA), spectroscopic, electrochemical and density functional theory calculations. A combination of supporting data from NMR spectroscopy, HR-MS and EA proved the formation of discrete triangular species as expected. The UV-vis spectro-

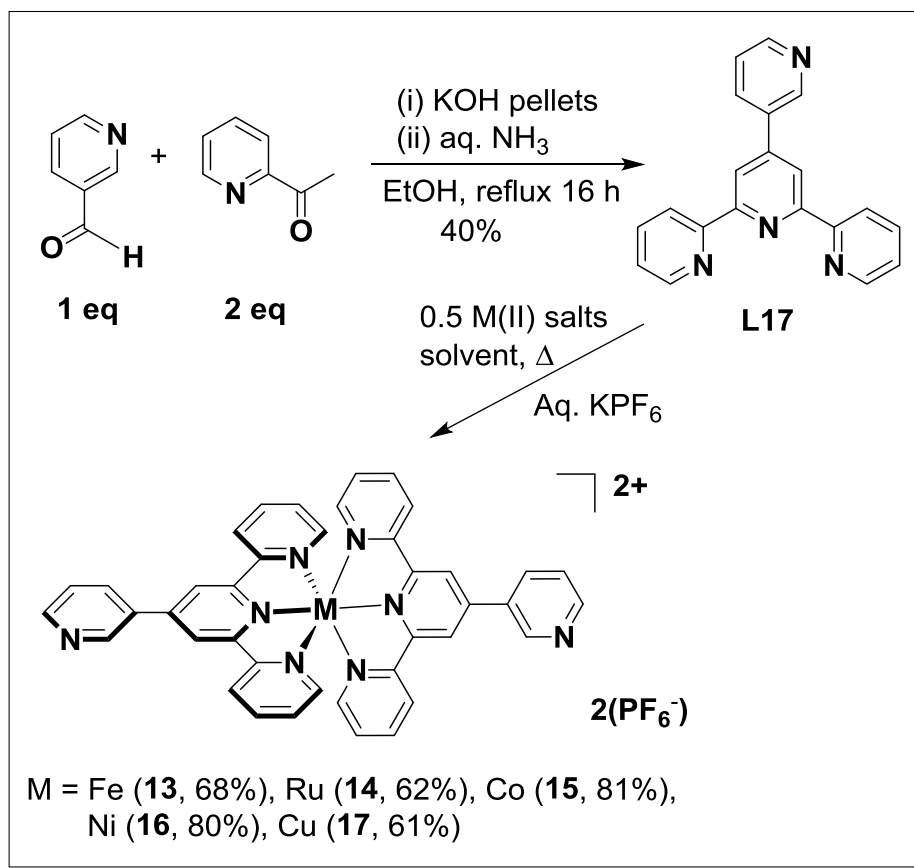

Scheme 4. Synthesis of 3-PyTpy and its homoleptic M(II)complexes. [25] 


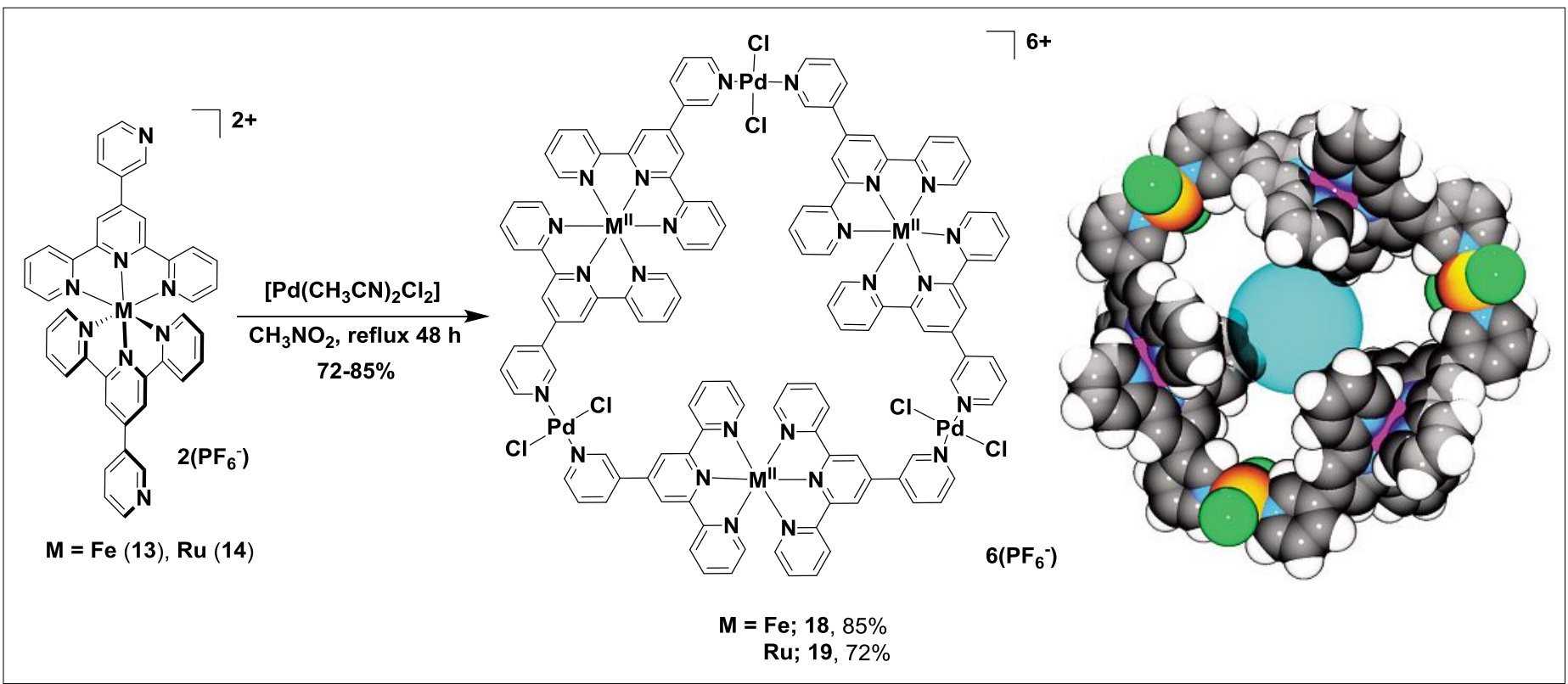

Scheme 5. Synthesis of hexametallic triangular assembly (left) and DFT optimized structure of the triangle indicating inclusion of a hollow sphere (right).[27]

scopic data suggested that the coordination of 3-pyridyl groups to neutral $\mathrm{PdCl}_{2}$ units barely affects the relative energies of the HOMO and LUMO compared to that of the uncoordinated metalloligands. Preliminary DFT data suggested the presence of pseudo $C_{3}$-symmetric cavities in the metallo-triangles, where the volume of the central cavity is $\sim 268-310 \AA^{3}$. The self-assembled products were found to be non-emissive at room temperature; however, the presence of cavities may be useful for inclusion of hosts (such as solvent, other neutral molecules with proper symmetry) in drug delivery.

Since complexes of tridentate tpy ligands and their self-assembled products were found to be mostly non-luminescent, we sought a way to develop tridentate ligands containing strong electron-donating guanidine moieties. A variety of methods to increase the energy gap between the emissive ${ }^{3}$ MLCT state and non-emissive ${ }^{3} \mathrm{MC}$ state are available in literature to increase the room temperature $\tau$ and $\Phi_{\mathrm{PL}}{ }^{[24,31]}$ such as (i) stabilization of the ${ }^{3}$ MLCT state by incorporation of electron-withdrawing functionalities ${ }^{[32]}$ and co-planar aromatic moieties, ${ }^{[33]}$ (ii) introduction of an organic chromophore to establish an equilibrium between the ${ }^{3} \mathrm{MLCT}$ and chromophore triplet ${ }^{3} \mathrm{LC}$ ( $\mathrm{LC}=$ ligand centred) states, ${ }^{[34]}$ (iii) tridentate neutral or anionic ligands that form six-membered chelate rings with transition metal ions, ${ }^{[35]}$ (iv) strongly donating carbene ${ }^{[36]}$ or (hetero)aromatic $\mathrm{N}^{\wedge} \mathrm{C}^{\wedge} \mathrm{N}$ type anionic ligands ${ }^{[37]}$ that destabilize the ${ }^{3} \mathrm{MC}$ state. We recently adopted a technique of introducing a new class of tridentate ligands, following approaches (iii) and (iv), and synthesized ligands L15 and L16 (Fig. 1). Heteroleptic Ru(II)- complexes (20-23) were synthesized from their $\mathrm{Ru}(\mathrm{III}) \mathrm{Cl}_{3}$ precursors ${ }^{[38]}$ in modest to good yields (Scheme 6) and their optoelectronic properties were studied in conjunction with solid-state structural determination and DFT studies. ${ }^{[39]}$ In the solid-state structures of 20-23, the N-Ru-N trans bite angles subtended by the ligand $\mathbf{L 1 5}$ were found to be $\sim 172^{\circ}$, which is substantially increased compared to that exhibited by the substituted tpy of dpt $\left(\sim 156^{\circ}\right)$. This fact is helpful in increasing the ligand field around the metal centre, so that the ${ }^{3} \mathrm{MC}$ state is increased in energy, thus facilitat-

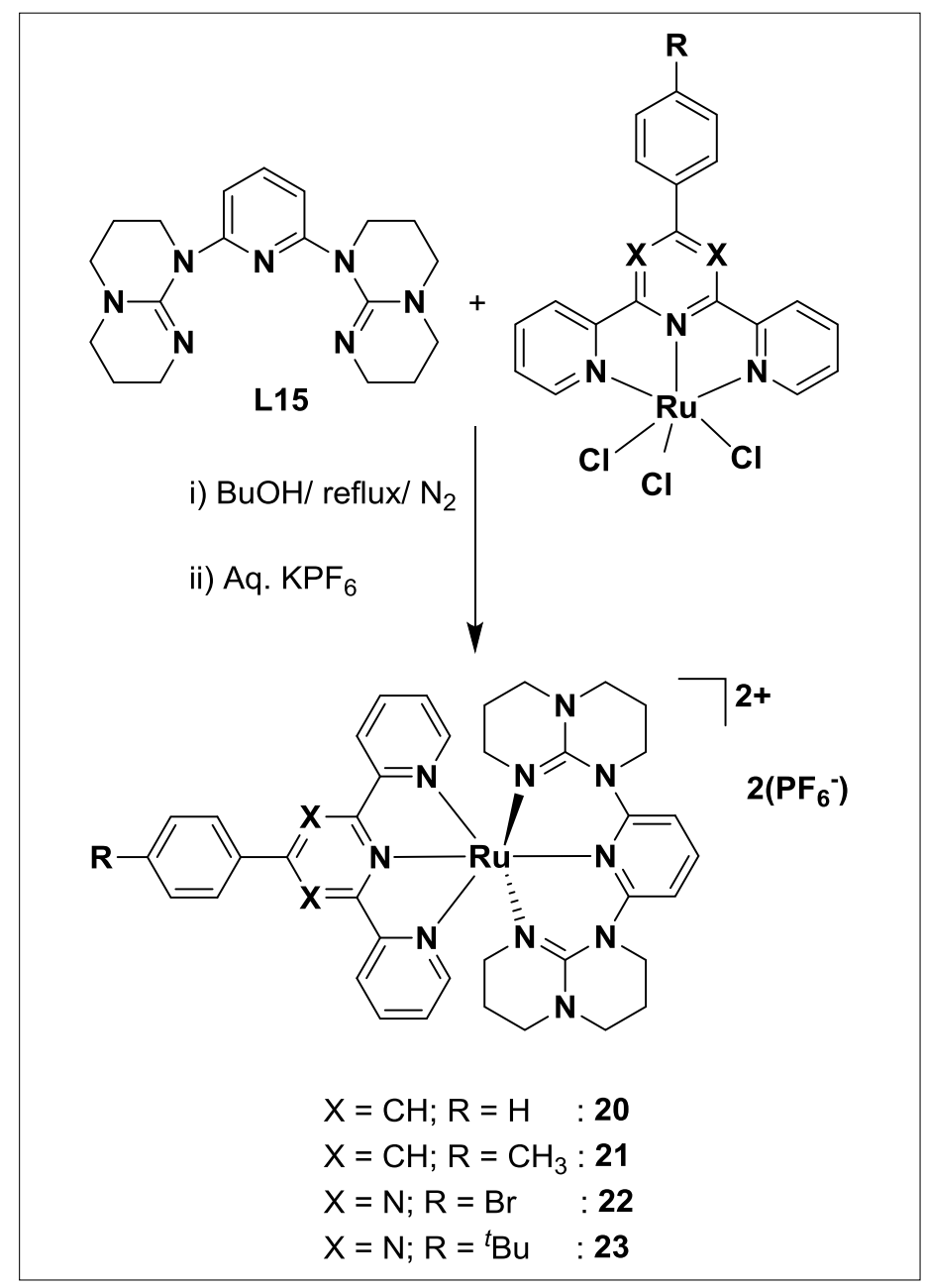

Scheme 6. Synthesis of heteroleptic $\mathrm{Ru}(\mathrm{II})$-complexes of tridentate ligands containing L15 and substituted tpy or dpt moieties. [39] 
ing improved room temperature photophysical properties of the complexes. The complexes exhibited metal-based quasireversible oxidations at $\sim 500-700 \mathrm{mV}$, which were found to be significantly lower than that of $\left[\mathrm{Ru}(\mathrm{tpy})_{2}\right]^{2+}(1.31 \mathrm{~V}$ vs. SCE $)$ and almost similar to the $\mathrm{Ru}^{3+} / \mathrm{Ru}^{2+}$-couple in $\left[\mathrm{Ru}(\text { tpy })\left(\mathrm{N}^{\wedge} \mathrm{C}^{\wedge} \mathrm{N}\right)\right]^{2+}\left(\right.$ where $\mathrm{N}^{\wedge} \mathrm{C}^{\wedge} \mathrm{N}=$ cyclometallating-1,3-di(2-pyridyl)benzene). This fact suggested that the presence of two hpp moieties in a pyridine heterocycle rendered the ligand $\mathbf{L 1 5}$ a strong donor as a negatively charged cyclometallating ligand. In UV-vis spectroscopy, the complexes exhibited lowest energy absorption at a far-red region $(620-740 \mathrm{~nm})$, which were assigned as ${ }^{1}$ MLCT transition as suggested by TD-DFT calculations of the complexes. This value is considerably red-shifted compared to the lowest energy absorption of $\left[\mathrm{Ru}(\mathrm{tpy})_{2}\right]^{2+}\left(\lambda_{\max }=474\right.$ $\mathrm{nm})$. Complexes $\mathbf{2 0}$ and $\mathbf{2 1}$ displayed the farthest bathochomically shifted ${ }^{3}$ MLCT emission, the nature of which was also supported by TD-DFT calculations, and these complexes are the first set of examples, to the best of our knowledge, to display such a low-energy emission as mononuclear Ru(II)-complexes containing tridentate ligands. Associated with the low-energy emission, the room temperature $\tau$ and $\Phi_{\mathrm{PL}}$ values were found to be $\sim 100 \mathrm{~ns}$ and $1 \times 10^{-3}$, respectively, for complexes $\mathbf{2 0}$ and 21, however complexes 22 and 23 were found to be non-luminescent at room temperature, but displayed ${ }^{3}$ MLCT emission at $77 \mathrm{~K}$ in an even lower energy (935-965 $\mathrm{nm}$ ) region. These photophysical data were shown to be due to strong donation and formation of six-membered chelate rings by the unsaturated hpp moieties.

Since the electrochemical and photophysical properties of complexes 20-23 were found to be unique and exciting, we were also interested in synthesizing the homoleptic complex of ligand L15. On this note, a homoleptic ruthenium complex of $\mathbf{L 1 5}$ was synthesized by microwave heating of 1 equiv. of $\mathrm{Ru}(\mathrm{DMSO}) \mathrm{Cl}_{2}$ and 2 equiv. of ligand $\mathbf{L 1 5}$ (Scheme 7). ${ }^{[40]}$ Complex 24 was isolated as an oxidized $\mathrm{Ru}(\mathrm{III})$-complex, and surprisingly, in the solid-state structure of complex $\mathbf{2 4}$, the $\mathrm{Ru}(\mathrm{III})$ ion was found to be facially coordinated byligand $\mathbf{L 1 5}$, unlike the typical meridional coordination exhibited by tpy- or dpt-type tridentate ligands. The complex showed a ligand-based quasi-reversible oxidation at $\sim 1.2 \mathrm{~V} v s$. SCE, and also displayed a metal-based $\left(\mathrm{Ru}^{3+} \rightarrow \mathrm{Ru}^{2+}\right)$ quasi-reversible reduction at a low-negative potential of $-0.29 \mathrm{~V}$. These values were also supported by DFT calculations, as the singly occupied molecular orbital (SOMO) and singly unoccupied molecular orbital (SUMO) were shown to be constituted predominantly by the ligand $\mathbf{L 1 5}$ and the metal centre, respectively. In UV-vis spectroscopy, complex $\mathbf{2 4}$ exhibited a transition at $326 \mathrm{~nm}$, which was found to be predominantly singlet ligand-to-metal charge transfer $\left({ }^{1} \mathrm{LMCT}\right)$ in nature, borrowing energy from higher energy LC transitions, as predicted by TD-DFT calculation of complex 24. The other lower energy transitions at $433 \mathrm{~nm}$ and 564(sh) nm (where sh = shoulder) were also found to be predominantly ${ }^{1} \mathrm{LMCT}$ in nature. Unfortunately, complex 24 was found to be non-emissive at room temperature due to the quenching of the excited-state in presence of the unpaired electron on the metal centre and also the LMCT states are known to undergo deactivation by radiationless decay.

$\operatorname{Re}(\mathrm{I})$-complexes of tridentate ligands have long been of interest due to their enriched photophysical activities. ${ }^{[41]}$ We thus sought to synthesize $\operatorname{Re}(\mathrm{I})(\mathrm{CO})_{3}$ complexes of ligands L15 and L16. ${ }^{[42]}$ Complexes 25 and 26 were synthesized by refluxing a mixture of $\left[\mathrm{Re}(\mathrm{CO})_{3} \mathrm{Br}\right]$ and ligand $\mathbf{L 1 5}$ or L16 in toluene in good yields (Scheme 8). In cyclic voltammetry, complexes $\mathbf{2 5}$ and 26 were found to be appealing as they exhibit three successive oxidations at $0.73 \mathrm{~V}$, $1.08 \mathrm{~V}$ and $1.43 \mathrm{~V}$, the first two of which were assigned to ligand-based oxidations, whereas the third quasi-reversible oxidation was ascribed to the oxidation of the metal centre. This metal-based oxidation occurs at $320 \mathrm{mV}$ less positive potential

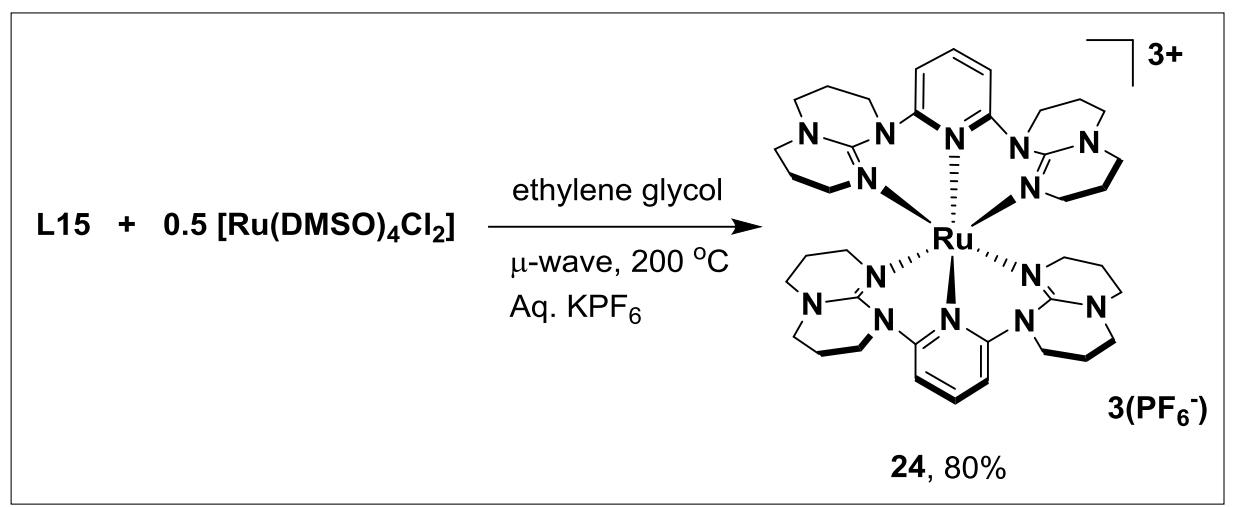

Scheme 7. Synthesis of homoleptic Ru(III)-complex of ligand L15. ${ }^{[40]}$

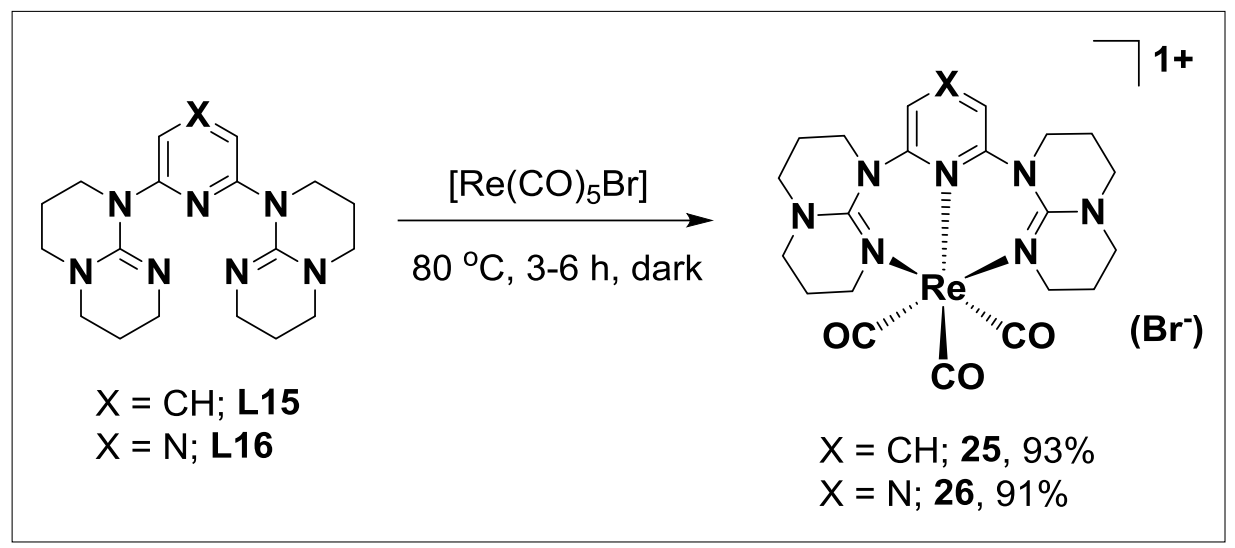

Scheme 8. Syntheses of $\operatorname{Re}(\mathrm{I})(\mathrm{CO})_{3}$ complexes of ligands $\mathbf{L 1 5}$ and L16. ${ }^{[42]}$ than in $\left[\operatorname{Re}(\mathrm{bpy})(\mathrm{CO})_{3}(\mathrm{Py})\right]^{+}$, suggesting that ligands $\mathbf{L 1 5}$ and $\mathbf{L 1 6}$ are more electron-donating than bpy and Py. In the cathodic region, ligand-based reductions were observed at $-1.99 \mathrm{~V}$ and $-1.49 \mathrm{~V}$, respectively, for complexes $\mathbf{2 5}$ and $\mathbf{2 6}$. Interestingly, due to broken $\pi$-conjugation between the hpp and the saturated heterocyclic moieties, as suggested by the solid-state structures of complexes $\mathbf{2 5}$ and $\mathbf{2 6}$, the metal-based oxidation was found to be fairly invariant to the changes in electronic The combined electron-donation from two hpp units was, therefore, the dominating factor in metal-based oxidation. This fact allowed ligand-based reductions to be separately tuned by simple modification of the electronic nature of the central aromatic rings in ligands L15 and L16. In the electronic absorption spectra of these complexes, the lowest energy transitions at 346-377 $\mathrm{nm}$ were observed and they were assigned as an admixture of LC (major) and ${ }^{1}$ MLCT (minor) transitions as suggested by TDDFT of these complexes. At room temperature complexes $\mathbf{2 5}$ and $\mathbf{2 6}$ were found to be blue-luminescent $\left(\lambda_{\max (\mathrm{MLCT})} \sim 400 \mathrm{~nm}\right)$ with associated excited-state lifetime of $\sim 10 \mathrm{~ns}$ at room temperature. properties of the pyridine or pyrazine unit. 


\section{Summary and Outlook}

Research by the author incorporates organic and inorganic synthesis with optoelectronic studies. In many cases, solid-state X-ray structural determination is also a valuable part of our analytical tools. Aside from the synthesis and investigation of optoelectronic studies of light-harvesting complexes, a supramolecular approach to the self-assembly of these chromophores is also an active research area being pursued. Other recent interests include reduction of proton sources and photocatalytic production of future fuels, such as $\mathrm{H}_{2}$, and also the development of novel dyes, that emit in NIR, for practical applications in dye-sensitized solar cells.

\section{Acknowledgements}

The author gratefully thanks Prof. Garry S. Hanan at the Department of Chemistry, Université de Montréal, to allow the research to be pursued in his laboratory. The author also thanks his coworkers and collaborators for their contributions cited in this article. Financial funding from Natural Sciences and Engineering Research Council of Canada (NSERC), the Centre for Self-Assembled Chemical Structure (CSACS), the Centre for Green Chemistry and Catalysis (CGCC), and personnel responsible for various analytical measurements as used in this research at the Université de Montréal are also gratefully acknowledged.

Received: May 27, 2015

[1] M. P. Coles, Chem. Commun. 2009, 3659.

[2] P. J. Bailey, S. Pace, Coord. Chem. Rev. 2001 214, 91

[3] a) K. A. Schug, W. Lindner, Chem. Rev. 2005 , 105, 67; b) M. D. Best, S. L. Tobey, E. V. Anslyn, Coord. Chem. Rev. 2003, 240, 3.

[4] a) F. A. Cotton, J. P. Donahue, N. E. Gruhn, D. L. Lichtenberger, C. A. Murillo, D. J. Timmons, L. O. V. Dorn, D. Villagrán, X. Wang, Inorg. Chem. 2006, 45, 201; b) F. A. Cotton, C. A. Murillo, X. Wang, C. C. Wilkinson, Inorg. Chem. 2006, 45, 5493 .

[5] G. M. Chiarella, F. A. Cotton, J. C. Durivage, D L. Lichtenberger, C. A. Murillo, J. Am. Chem Soc. 2013, 135, 17889 .
[6] F. A. Cotton, G. M. Chiarella, N. S. Dalal, C. A. Murillo, Z. Wang, M. D. Young, Inorg. Chem. 2010, 49, 319.

[7] a) M. P. Coles, Dalton Trans. 2006, 985; b) M. S. Khalaf, M. P. Coles, P. B. Hitchcock, Dalton Trans. 2008, 4288; c) B. M. Day, M. P. Coles, P. B. Hitchcock, Eur. J. Inorg. Chem. 2012, 841.

[8] a) P. J. Aragón-Sáez, S. H. Oakley, M. P. Coles, P. B. Hitchcock, Chem. Commun. 2007, 816; b) M. S. Khalaf, S. H. Oakley, M. P. Coles, P. B. Hitchcock, Cryst. Eng. Comm. 2008, 10, 1653.

[9] M. P. Coles, M. S. Khalaf, P. B. Hitchcock, Inorg. Chim. Acta 2014, 422, 228.

[10] M. P. Coles, P. J. Aragón-Sáez, S. H. Oakley, P. B. Hitchcock, M. G. Davidson, Z. B. Maksic, R. Vianello, I. Leito, I. Kaljurand, D. C. Apperley, J. Am. Chem. Soc. 2009, 131, 16858

[11] T.-G. Ong, G. P. A. Yap, D. S. Richeson, Chem. Commun. 2003, 2612.

[12] R. E. Tundel, K. W. Anderson, S. L. Buchwald, J. Org. Chem. 2006, 71, 430.

[13] C. Sabot, K. A. Kumar, S. Meunier, C. Mioskowski, Tetrahedron Lett. 2007, 48, 3863.

[14] a) A. Huczynski, B. Brzezinski, '1,5,7-Triazabicyclo[4.4.0]dec-5-ene', in e-EROS Encyclopedia of Reagents for Organic Synthesis, John Wiley \& Sons, Ltd. 2008, doi:10.1002/047084289X.rn00786. b) 'Superbases for Organic Synthesis: Guanidines, Amidines, Phosphazenes and Related Organocatalysts', Ed. T. Ishikawa, 2009, John Wiley \& Sons, Ltd. ISBN: 978-0-470-51800-7.

[15] B. M. Day, N. E. Mansfield, M. P. Coles, P. B Hitchcock, Chem. Commun. 2011, 47, 4995.

[16] A. K. Pal, P. K. Mandali, D. K. Chand, G. S. Hanan, Synlett 2015, 26, 1408.

[17] a) S. Nag, J. G. Ferreira, L. Chenneberg, P. D. Ducharme, G. S. Hanan, G. L. Ganga, S. Serroni, S. Campagna, Inorg. Chem. 2011, 50, 7; b) A. K. Pal, S. Nag, J. M. Ferreira, V. Brochery, G. L. Ganga, A. Santoro, S. Serroni, S. Campagna, G. S. Hanan, Inorg. Chem. 2014, 53, 1679.

[18] A. K. Pal, P. D. Ducharme, G. S. Hanan, Chem. Commun. 2014, 50, 3303.

[19] M. I. J. Polson, G. S. Hanan, N. J. Taylor, B. Hasenknopf, R. Thouvenot, Chem. Commun. 2004, 1314.

[20] A. K. Pal, G. S. Hanan, Dalton Trans. 2014, 43, 6567.

[21] a) J. W. Slater, D. M. D'Alessandro, F. R Keene, P. J. Steel, Dalton Trans. 2006, 16, 1954; b) S. Serroni, S. Campagna, R. P. Nascone, G. S. Hanan, G. J. E. Davidson, J.-M. Lehn, Chem. Eur. J. 1999, 5, 3523; c) K. O. Johansson, J. A. Lotoski, C. C. Tong, G. S. Hanan, Chem. Commun. 2000, 819.

[22] M. R. Gill, J. Garcia-Lara, S. J. Foster, C.
Smythe, G. Battaglia, J. A. Thomas, Nat. Chem. 2009, 1,662 .

[23] K. Hasan, A. K. Pal, E. Zysman-Colman, G. S. Hanan, Chem. Commun. 2015, 51, 14060.

[24] A. K. Pal, G. S. Hanan, Chem. Soc. Rev. 2014, 43, 6184 .

[25] A. K. Pal, B. Laramée-Milette, G. S. Hanan, Inorg. Chim. Acta 2014, 418, 15.

[26] J. Wang, G.S. Hanan, Synlett 2005, 1251.

[27] A. K. Pal, B. Laramée-Milette, G. S. Hanan, RSC Adv. 2014, 4, 21262.

[28] a) R. Chakrabarty, P. S. Mukherjee, P. J. Stang, Chem. Rev. 2011, 111, 6810; b) T. R. Cook, P. J. Stang, Chem. Rev. 2015, 115, 7001.

[29] a) H. Takezawa, T. Murase, G. Resnati, P. Metrangolo, M. Fujita, J. Am. Chem. Soc. 2014, 136, 1786 and references cited therein; b) J. E. Beves, D. A. Leigh, Nat. Chem. 2010, 2, 708; c) S. S. Sun, A. Kumar, A. J. Lees, Coord. Chem. Rev. 2008, 252, 922 and references cited therein.

[30] a) M-P Santoni, A. K. Pal, G. S. Hanan, M.C. Tang, K. Venne, A. Furtos, P. MénardTremblay, C. Malveaua, B. Hasenknopf, Chem. Commun. 2012, 48, 200; b) M-P Santoni, A. K. Pal, D. Chartrand, G. S. Hanan, P. MénardTremblay, M.-C. Tang, K. Venne, A. Furtos, B. Hasenknopf, Inorg. Chem. 2014, 53, 10039.

[31] E. A. Medlycott, G. S. Hanan, Coord. Chem. Rev. 2006, 250, 1763.

[32] M. Maestri, N. Armaroli, V. Balzani, E. C. Constable, A. M. W. C. Thompson, Inorg. Chem. 1995, 34, 2759.

[33] M. I. J. Polson, E. A. Medlycott, G. S. Hanan, L. Mikelsons, N. J. Taylor, M. Watanabe, Y. Tanaka, F. Loiseau, R. Passalacqua, S. Campagna, Chem. Eur. J. 2004, 10, 3640.

[34] R. Passalacqua, F. Loiseau, S. Campagna, Y.Q. Fang, G. S. Hanan, Angew. Chem., Int. Ed. 2003, 42, 1608.

[35] a) M. Abrahamsson, M. Jäger, R. J. Kumar, T. Oesterman, P. Persson, H.-C. Becker, O. Johansson, L. Hammarström, J. Am. Chem. Soc. 2008, 130, 15533; b) J.-L. Chen, Y. Chi, K. Chen, Y.-M. Cheng, M.-W. Chung, Y.-C. Yu, G.-H. Lee, P.-T. Chou, C.-F. Shu, Inorg. Chem. 2010, 49, 823

[36] D. G. Brown, N. Sanguantrakun, B. Schulze, U. S. Schubert, C. P. Berlinguette, J. Am. Chem. Soc. 2012, 134, 12354.

[37] S. H. Wadman, J. M. Kroon, K. Bakker, R. W. A. Havenith, G. P. M. van Klink, G. van Koten, Organometallics 2010, 29, 1569.

[38] M.-P. Santoni, A. K. Pal, G. S. Hanan, A Proust, B. Hasenknopf, Inorg. Chem. Commun. 2011, 14, 399.

[39] A. K. Pal, S. Serroni, N. Zaccheroni, S. Campagna, G. S. Hanan, Chem. Sci. 2014, 5 , 4800.

[40] A. K. Pal, N. Zaccheroni, S. Campagna, G. S. Hanan, Chem. Commun. 2014, 50, 6846.

[41] a) R. V. Slone, D. I. Yoon, R. M. Calhoun, J. T. Hupp, J. Am. Chem. Soc. 1995, 117, 11813; b) A. G. Bonn, M. Neuburger, O. S. Wenger, Inorg. Chem. 2014, 53, 11075.

[42] A. K. Pal, G. S. Hanan, Dalton Trans. 2014, 43, 11811. 